\title{
Instituto de Sistemas Fotovoltaicos de Concentración concentration photovoltaics hybrid system first year of operation and improvements
}

\author{
Pablo Jesus Trujillo Serrano , Cesareo Alamillo Davila , Maria Martínez Montes \\ Oscar de la Rubia , Francisca Rubio , Daniel Masa-Bote, Manuel Castillo-Cagigal \\ Eduardo Matallanas ，Estefania Caamaño-Martín and Alvaro Gutiérrez
}

\begin{abstract}
A photovoltaic (PV) hybrid system combines PV with other forms of electricity generation, usually a diesel generator. The system presented in this paper uses concentration photovoltaic (CPV) as the main generator in combination with a storage system and the grid, configured as the backup power supply. The load of the system consists of an air conditioning system of an office building. This paper presents the results obtained from the first months of operation of the CPV hybrid system installed at Instituto de Sistemas Fotovoltaicos de Concentración facilities together with exhaustive simulations in order to model the system behaviour and be able to improve the self-consumption ratio. This system represents a first approach to the use of a CPV in office buildings complemented by an existing AC-coupled hybrid system. The contribution of this paper to the analysis of this new system and the existing tools available for its simulation, at least a part of it, can be considered as a starting point for the development of these kinds of systems. Copyright (c) 2013 John Wiley \& Sons, Ltd.
\end{abstract}

KEYWORDS

CPV; hybrid system; off-grid; self-consumption

\section{INTRODUCTION}

Concentration photovoltaics (CPV) technology is being developed nowadays as a solution for generating electricity in big scale projects connected to the grid. Simultaneously, new modes of operation, such as stand-alone or hybrid systems, are being studied [1]. Hybrid systems, using an additional power supply to PV generator, have been mainly developed for their use in remote areas. However, self-consumption policies [2,3], modifications in the regulation of the grid connection, rising prices of retail electricity and reduction of costs are helping to establish these kinds of systems in places where the utility grid is available to reduce the cost of electricity.

The self-consumption represents the electrical energy consumed by the load that is supplied by the local generation sources, and its effects have been analysed in previous studies using other PV generation technologies [4,5]. CPV technology is becoming an option for self-consumption, taking advantage of the improvement capacity of this technology and the high efficiencies already achieved.

For this reason, Instituto de Sistemas Fotovoltaicos de Concentración (ISFOC) installed a CPV hybrid system in its office building [6]. This system is used to test CPV as an off-grid application and, at the same time, it gives the opportunity to self-consume its generated electricity in the premises of the ISFOC, reducing the electricity cost. An air conditioning and heating system servicing the offices has been connected to the hybrid system, acting as a load. A preliminary study on this system was carried out by the authors [7]. As a result of this study, several modifications have been performed to the system.

This paper presents an analysis carried out on the hybrid system installed in the ISFOC. The objective of this 
analysis is to assess the performance of the system and explore the possibilities of CPV technology for selfconsumption, because this operational mode offers new possibilities and may open new markets for this technology. In addition, the improvements of electricity storage and demand-side management over the performance of the hybrid system in terms of increased self-consumption and reduction of energy exchanges with the grid have been explored as well. It has been also studied the possibility to add additional loads to the hybrid system - lightning, office appliances - with the objective to bring the loads supplied by the system closer to the actual loads found in an office carried out to assess the system performance modifications, which will be explained in the following pages.

The remainder of this paper is as follows. Section 2 describes the system requirements, including the CPV characteristics, the consumptions and the energy balances. In Section 3, the complete system installed at ISFOC is described. Section 4 presents simulation results, which provide information about the system behaviour. Section 5 shows the real behaviour of the system. Finally, Section 6 concludes this paper.

\section{PREVIOUS CONSIDERATIONS}

Some considerations were taken into account in order to know how the system would behave, and they are presented in this section. First, the differences between the generation profile of CPV and PV must be considered in order to do a proper management of the system. The CPV generation profile and different load consumption profiles are analysed to size the installation. It is important to take into account the storage capacity to determine how sensitive the system will be to differences in the profiles from the generation to the load consumption. Finally, the analysis of the electricity balance carried out is presented.

\subsection{Concentration photovoltaics versus photovoltaics}

The goal of CPV is to significantly reduce the cost of PV electricity by replacing expensive PV converter area with less expensive optical material that concentrates sunlight onto highly efficient PV cells. This approach allows for a reduction in the cell area required for producing a given amount of power and provides the opportunity to use higher performance PV cells that would be cost prohibitively without concentration [8]. These high-performance multi-junction solar cells are optimised to work under high concentrations with efficiencies higher than traditional silicon cells $[9,10]$. Moreover, this technology seems to have a long path to travel in terms of increasing its efficiency as it is published by NREL in the 'Best research-cell efficiencies' [11], being the current world solar cell efficiency record, $43.5 \%$, set by the company Solar Junction in 2011 .

It is the use of these already mentioned optics systems that makes mandatory the use of two-axis trackers in high concentration PV, because only Direct Normal Irradiance (DNI) is used as the energy input whereas a PV system mounted on a two-axis tracker uses the Global Normal Irradiance (GNI).

Figure 1 shows the difference between clear and cloudy sky conditions in terms of DNI, GNI and CPV power output. Figure 1(a) represents clear sky conditions where the behaviours of DNI (in red) and GNI (in green) are the same, and the output power of a CPV module (in blue) has also a similar trend.

Because DNI represents only the portion of light from GNI that comes directly from the sun, it is less stable than that of GNI, due to phenomena such as scattering, which changes the direction of the sun rays. Therefore, the energy production of CPV is affected as well by these phenomena. In Figure 1(b), a cloudy day is considered; it can be seen that the DNI drops are bigger than the GNI ones and the output power of the CPV goes to zero when DNI goes to $200 \mathrm{~W} / \mathrm{m}^{2}$ and GNI goes to $400 \mathrm{~W} / \mathrm{m}^{2}$.

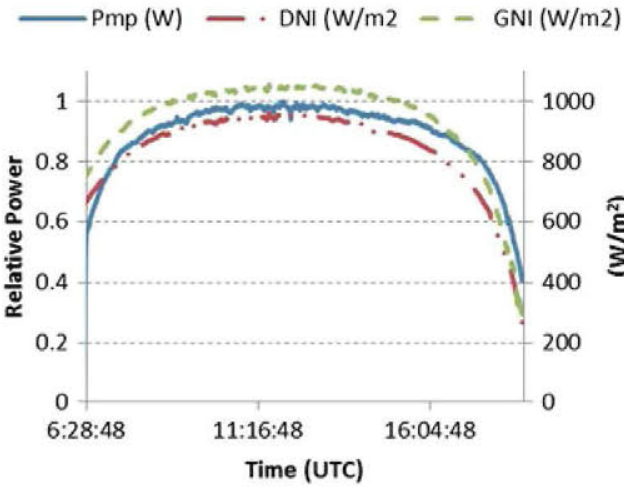

(a)

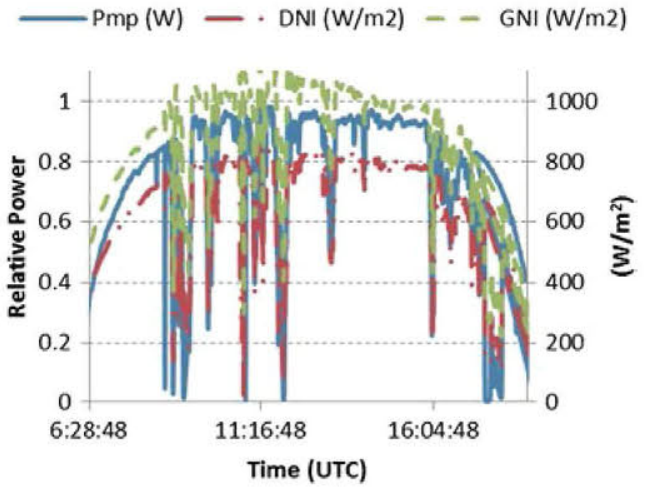

(b)

Figure 1. Global normal irradiance, direct normal irradiance and concentration photovoltaics normalised power for (a) a clear sky day and (b) a cloudy day. 
In summary, despite some limitations in the performance; the better efficiencies are achieved in CPV; the world record at CPV module is $33.9 \%$ measured at $1000 \mathrm{~W} / \mathrm{m}^{2}$ and $25^{\circ} \mathrm{C}$ cell temperature achieved by Siemens-Semprius in 2012 [12], and its big path of improvement makes this kind of system an interesting option for the near future.

\subsection{Generation and load consumption profiles analysis}

Instituto de Sistemas Fotovoltaicos de Concentración is a research and development (R\&D) institute located in the Spanish town of Puertollano (latitude: $38^{\circ}$ ), whose main objective is to promote the CPV industrialization [13]. For this purpose, different CPV plants have been installed and connected to the grid to analyse their performance. These CPV plants have been operating since 2008, therefore, in 2012, more than 3 years of real production data and solar resource measurements are available. These data have been used to generate a 'typical year' for the energy production of a $100-\mathrm{kW}$ CPV plant and solar resource, to be used as an input when simulating the system. Figure 2 is a representation of this typical year calculated in

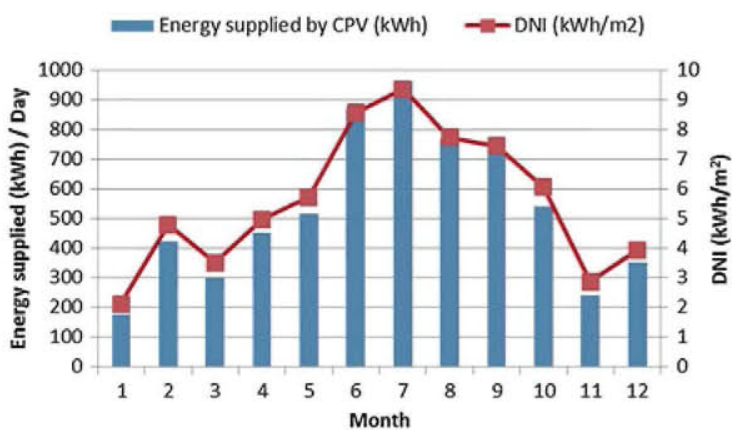

Figure 2. Average daily generation of a $100-\mathrm{kW}$ concentration photovoltaics plant in Puertollano for the different months of the year together with the average daily direct normal irradiance.

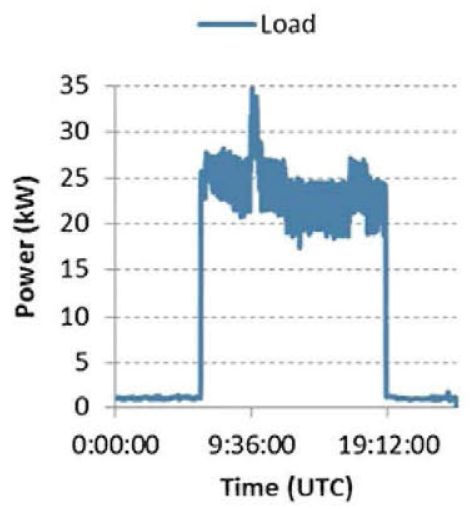

(a)
Puertollano. It has been calculated averaging the energy production of a $100-\mathrm{kW}$ CPV plant in Puertollano $\left(850 \mathrm{~W} / \mathrm{m}^{2} \mathrm{DNI} @ 25^{\circ} \mathrm{C}\right.$ cell temperature) in the years 2009-2011.

Since September 2011, the consumption profile of the air conditioning system has been analysed, taking into account the differences existing between seasons. The load consumption of an office building is different between working days and non-working days; for a first approach, only working days are considered. It has been observed that the consumption during the summer working hours is quite constant (Figure 3(a)). However, in winter, there is a gap of time in the morning, when the consumption is bigger than the rest of the working hours, and it also presents some peaks along the day (Figure 3(b)). During the winter, it is necessary to heat the building in the morning until it reaches the target temperature consuming a great amount of energy, and the rest of peaks are for maintaining the building temperature between the limits. In spring and autumn, the consumption is lower and changing; however, it never reaches zero, as Puertollano has not a mild climate.

In Figure 4(a), the average daily load consumption for working days is presented for the different months of the year. It is remarkable that the consumption is much higher in summer, when the building has to be cooled than in winter when it has to be heated. For these calculations, there were no data available from June to August, so the consumption in these months was estimated using the data of the first days of September and end of June.

In addition, other loads are being studied (lighting, computers, kitchen...) in order to analyse its profile and maintain them as a reserve to connect them to the hybrid system in the future, to improve the correlation between consumption and CPV generation.

To dimension the storage capacity, a rough approach has been used to calculate the capacity of the battery banks described in Equation (1):

$$
C_{S}=\frac{C_{n} \cdot D O D_{\max }}{L}
$$

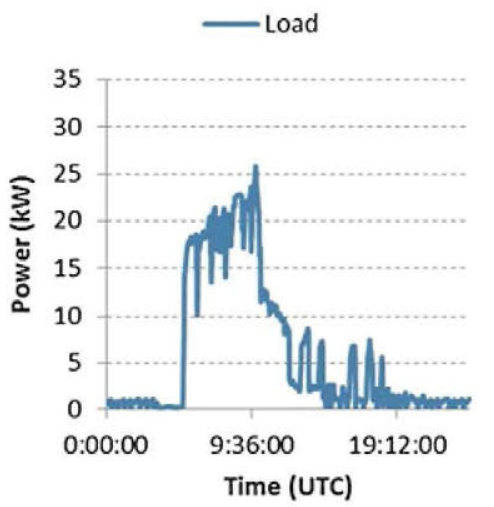

(b)

Figure 3. Typical daily consumption profiles for (a) summer (b) winter. 


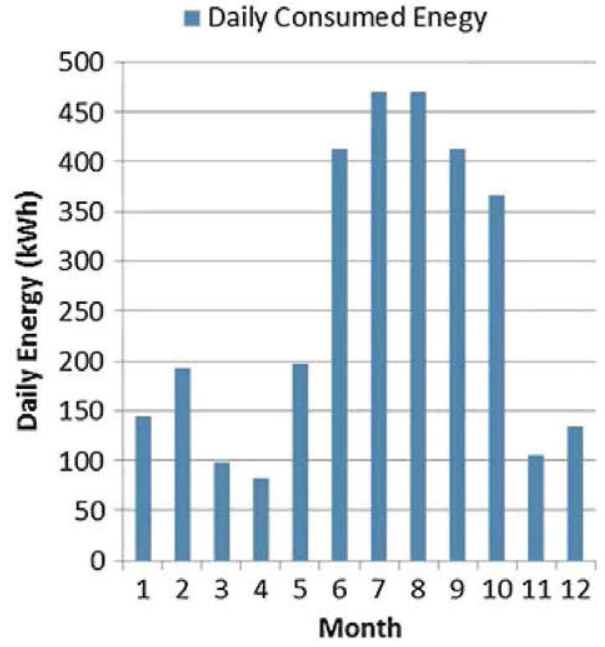

Figure 4. Daily energy consumed by the load averaged every month.

where $C_{\mathrm{s}}$ represents the number of autonomy days of the batteries, $C_{\mathrm{n}}$ is the nominal capacity of the batteries $(\mathrm{kWh})$, $D O D_{\max }$ is the maximum possible depth of discharge (\%) and $L$ is the daily energy needed by the load $(\mathrm{kWh})$.

The criterion followed is to take into account the month in which the consumption is maximum (July and August, daily consumption of $405 \mathrm{kWh}$ ) and 1 day of autonomy with a maximum depth of discharge of the batteries of a $60 \%$. With these considerations, the capacity of the battery bank should be $675 \mathrm{kWh}$ ( 3 banks of $48 \mathrm{~V}$ with a capacity of $4687 \mathrm{Ah}$ for each cell of $2 \mathrm{~V}$ ). However, this size of battery bank is cost prohibitive (more than $€ 115000$ ), so, the challenge is to operate this system with a much smaller battery size.

\subsection{Electricity balance}

Finally, some previous calculations were carried out analysing different electricity balance scenarios of the system between the CPV generation and the local demand defining the operation of the hybrid system.
In particular, the net electricity ratio (NER) parameter defines the size ratio between the CPV generator and the local loads, as described in Equation (2):

$$
N E R=\frac{E_{P V}}{E_{\text {Load }}}
$$

where, $\backslash E_{\mathrm{PV}} \backslash$ is the PV energy generated, and $E_{\mathrm{Load}}$ is the electricity consumed by the loads.

Because NER is normalised by the load demand, it allows comparing systems with different sizes and loads. The NER range is $[0, \infty) ; N E R=0$ would mean no local generation available, and $N E R \rightarrow \infty$ would be the case with no local demand.

Net electricity ratio calculations have been carried out for different CPV generators nominal power. The real generation profile presented as the 'typical year' in the previous section has been used as the reference generation being then scaled for different nominal powers. The load profile used is the air-conditioning consumption measured at the ISFOC facilities aforementioned. The monthly NER is shown in Figure 5, and the yearly values are represented in Table I.

Although NER is greater than 1 , it does not imply that the system does not consume energy from the grid, because this parameter does not take into account the time distribution of the generation and demand. This time correlation between CPV generation and consumption is evaluated by the self-consumption factor $(\xi)$. It represents the energy consumed by the loads that is directly supplied by the local generation sources [4]. When the system is

Table I. Yearly net electricity ratio and self-consumption factor for different concentration photovoltaics nominal powers.

\begin{tabular}{lllllll} 
& $10 \mathrm{~kW}$ & $20 \mathrm{~kW}$ & $30 \mathrm{~kW}$ & $40 \mathrm{~kW}$ & $50 \mathrm{~kW}$ & $60 \mathrm{~kW}$ \\
\hline NER & 0.27 & 0.54 & 0.81 & 1.08 & 1.35 & 1.62 \\
$\xi$ without storage & 0.19 & 0.34 & 0.46 & 0.51 & 0.53 & 0.54 \\
$\xi$ with 45-kWh & 0.26 & 0.5 & 0.7 & 0.88 & 0.91 & 0.92 \\
storage & & & & & & \\
\hline
\end{tabular}

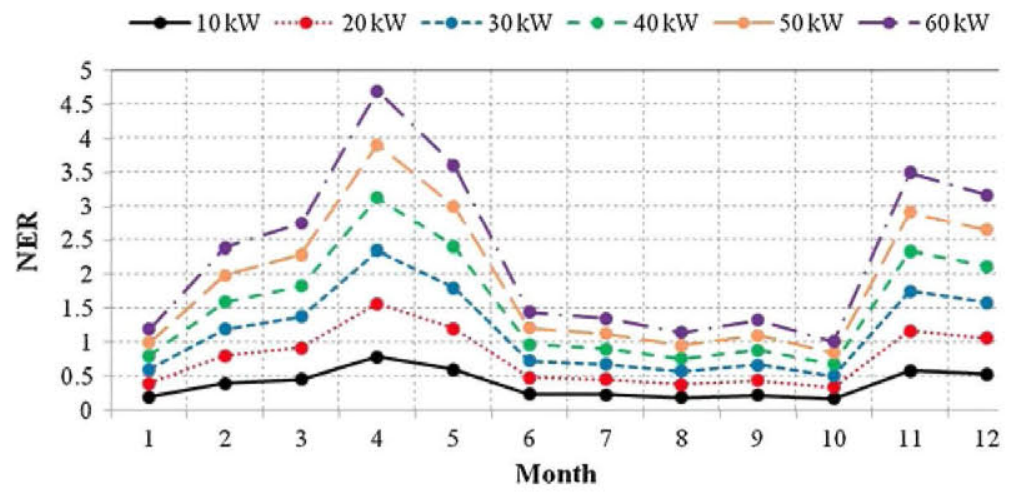

Figure 5. Monthly net electricity ratio for different concentration photovoltaics nominal powers. 
equipped with a storage system, some of the energy can be stored in order to use it when it is demanded. Therefore, the energy consumed from the battery that comes from the CPV generation is also considered as self-consumed energy. The next equation defines the self-consumption factor:

$$
\xi=\frac{E_{P V, \text { Load }}+E_{\text {Bat }, \text { Load }}}{E_{\text {Load }}}
$$

where, $E_{\mathrm{PV}, \text { Load }}$ is the PV energy that feeds directly the loads, and $E_{\mathrm{Bat}, \mathrm{Load}}$ is the PV energy imported from the battery to the loads.

This parameter is also normalised by the load demand so that it allows comparing systems with different sizes and loads. The $\xi$ range is $[0,1] ; \xi=0$ would be the case of no local generation available and $\xi=1$ when all the demand is supplied by the local PV generation.

The self-consumption factor has been calculated for different CPV generators nominal power, too.

Initially, the monthly self-consumption factor has been calculated without taking into account the storage system, which represents the natural self-consumption and it is presented in Figure 6, and the yearly values are shown in Table I.
The use of storage techniques in hybrid systems increases considerably the self-consumption factor [5] as can be seen in Figure 7, mainly in winter, when although the consumption is smaller, its maximum does not coincide with the maximum CPV generation.

The comparison of the yearly values for the NER and self-consumption factor with and without storage for different nominal powers can be observed in Table I.

In Spain, the terms and conditions to feed energy to the grid for these kinds of systems are still not completely regulated, so the energy generated that is not consumed by the local loads (NER $>1$ ) will be unused energy. Once the self-consumption policies change, it will be possible to feed this excess of energy to the grid. This fact will make available systems without a storage system or with a smaller one, which will make possible to have this kind of systems with a smaller initial investment.

\section{HYBRID SYSTEM DESCRIPTION}

This section describes the system, emphasising in its main elements, the system management, the main and backup generator, the storage system, and the monitoring equipment.

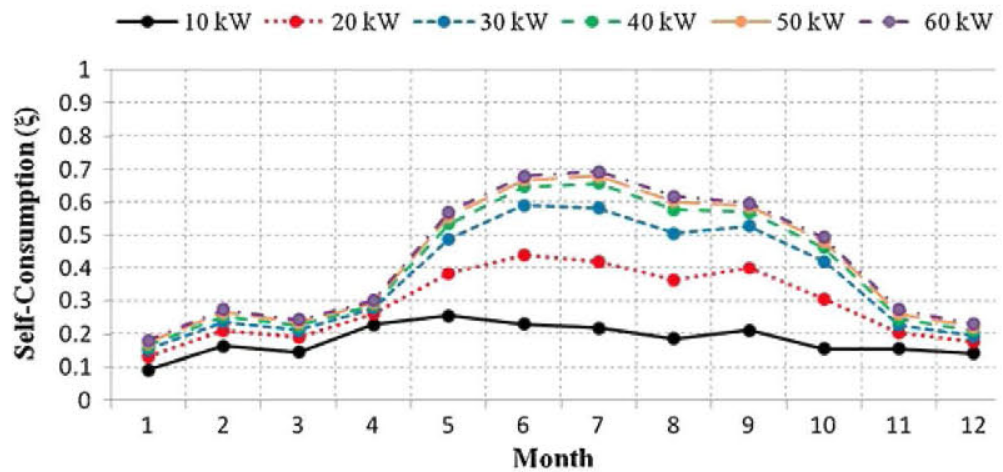

Figure 6. Self-consumption factor without storage system for different concentration photovoltaics nominal powers.

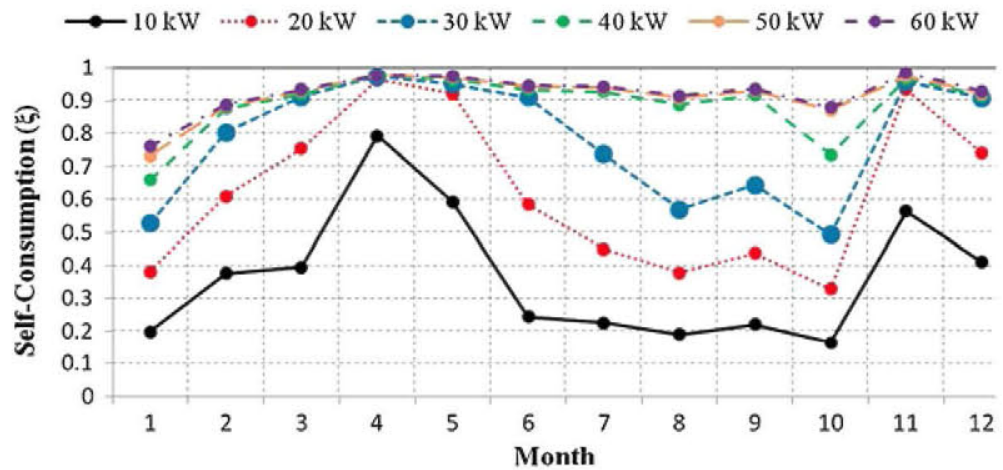

Figure 7. Self-consumption factor with $45-\mathrm{kWh}$ storage system for different concentration photovoltaics nominal powers. 


\subsection{System management}

The system is based in SMA hybrid system technology. The three-phase multicluster-box is the solution of SMA for large off-grid hybrid systems, based on AC coupling between generation, storage, backup generator and local loads [14]. One of its main characteristics is its scalability, because the maximum power of the installation can be increased by adding more clusters in parallel. This scalability is obtained because all the loads and generators are AC-coupled as it is shown in Figure 9.

The system installed at ISFOC uses a MulticlusterBox 12, which means that it is able to have 12 off-grid inverters (Sunny Island type) and manages up to $110 \mathrm{~kW}$ power (generator and loads). However, the maximum energy that can be taken from the batteries is harder to determine, because the peak power that can manage the system varies from 36 to $108 \mathrm{~kW}$ depending on the temperature and the period in which the system has to manage this energy for the number of Sunny Island inverters installed.

At the moment, this system has nine Sunny Island inverters, three for each phase. This is the most important piece of the installation, because it creates the grid and manages all the energy flows from the CPV generator, the batteries and the utility grid, depending on the solar resource available to meet the demand in each moment, exchanging energy, if necessary, with the batteries. When demand is lower than the available generation, and the batteries are full-charged, the Sunny Island inverters, which monitor all energy flows within the system, command the generator inverters to polarise the CPV generators away from the maximum power point to accommodate generation and consumption.

A basic scheme of the system is presented in Figure 8.
The CPV hybrid system has been running since September 2011. Over these first months, it has been working as a demonstration project in order to test different loads and profiles and to establish the improvements and final design of the installation. During this first phase, the connection and disconnection of the system to the grid (backup generator) has been manually performed to assure that there is no power cut-off of the air conditioning system. Once it has been tested, an automatic contactor is installed to be able to connect/disconnect the backup generator from the system, introducing the charge level of the batteries as the input for this connection.

\subsection{Main generator}

The main generator will be built in phases so it can be easily modified including different CPV technologies whose performances will also be analysed.

At the beginning, the CPV generator was based on DAIDO Steel modules mounted in one frame of the Titan Tracker (Figure 9(a)), its nominal power was $24 \mathrm{~kW}$. This first CPV generator has been operating since September 2011 until February 2012.

At that moment, it was planned to increase the CPV generator power from 24 to $58 \mathrm{~kW}$, for testing three different CPV technologies and to be able to supply electricity to different loads. In May 2012, three new concentrators were installed and the initial $24-\mathrm{kW}$ concentrator was dismantled in order to replace the tracker for an improved and smaller version. The nominal power of the resulting CPV generator is $34 \mathrm{~kW}$. The new concentrators belong to two different suppliers (Siemens-Semprius, Figure 9(b) and Isofotón Gen2, Figure 9(c)).

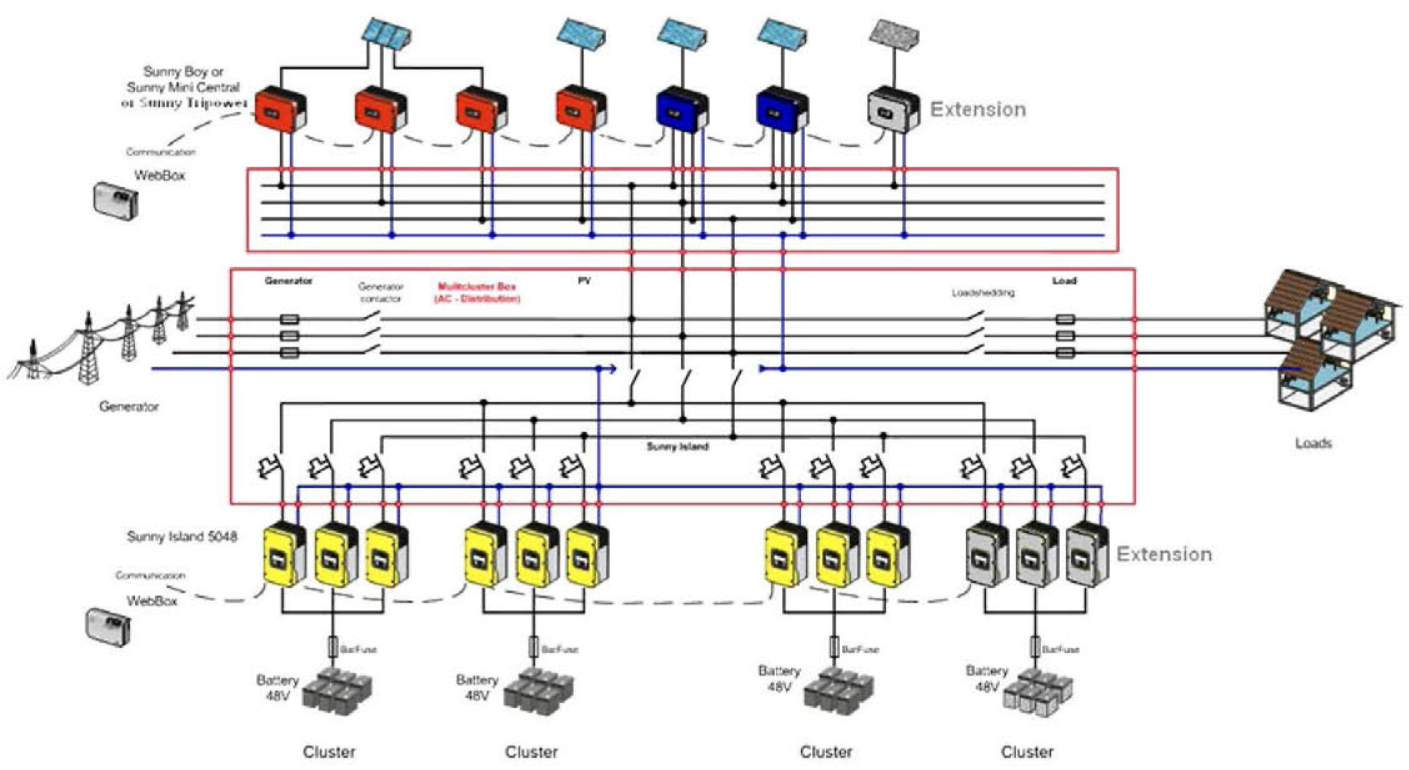

Figure 8. Hybrid system basic scheme (source: SMA). 


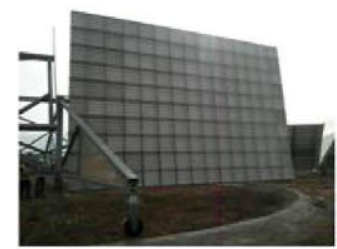

(a)

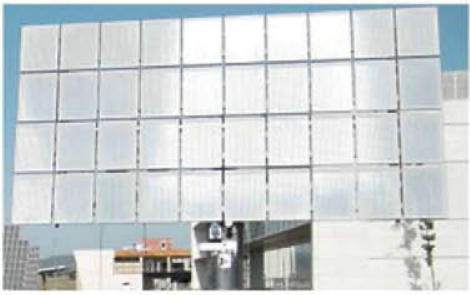

(b)

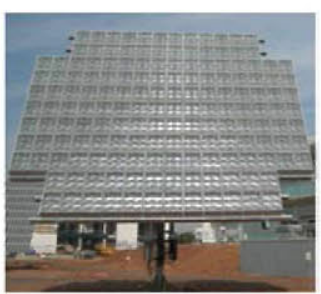

(c)

Figure 9. Concentration photovoltaics generators connected to the ISFOC Hybrid System (a) Daido, (b) Siemens-Semprius, (c) Isofotón Gen2.

Finally, during the summer, a new and smaller Titan Tracker with DAIDO modules has been installed, although it is not yet connected to the hybrid system. This new concentrator completes the CPV system to its designed $58 \mathrm{~kW}$.

\subsection{Backup generator}

The backup generator is the utility grid, therefore, there is always energy available to supply to the loads. Currently, the system is configured to avoid feeding energy to the grid; perhaps in the near future, when the regulation about the self-consumption is approved in Spain, this system will be able to feed the excess of energy to the grid instead of wasting it, which will make easier the management of the system.

\subsection{Batteries}

The chosen batteries are lead acid with gas recombination system. They are divided into three battery banks (Figure 10), one for each cluster, with a capacity of $800 \mathrm{Ah}$ and $48 \mathrm{~V}$, which means up to $115 \mathrm{kWh}$ of stored energy. This capacity is much smaller than the $674-\mathrm{kWh}$ calculated earlier, because its cost was prohibitive for the project.

Therefore, this limitation in the storage capacity introduces an additional challenge for the managing of the system, because the storage is much smaller than that needed for managing the energy.

\subsection{Monitoring system}

Different monitoring equipment has been installed in order to analyse the quality of the grid and the energy flows of the system. The objective is to improve the final management to obtain the maximum profit of the CPV electricity generation.

The AC circuits are monitored with grid quality analyzers. The SMA inverters also provide valuable information about the status of the installation, such as the batteries' state of charge, temperature and power/energy flows.

Finally, meteorological data are obtained from the ISFOC meteorological station, which includes DNI, GNI, ambient temperature, wind, solar spectrum, and so on.

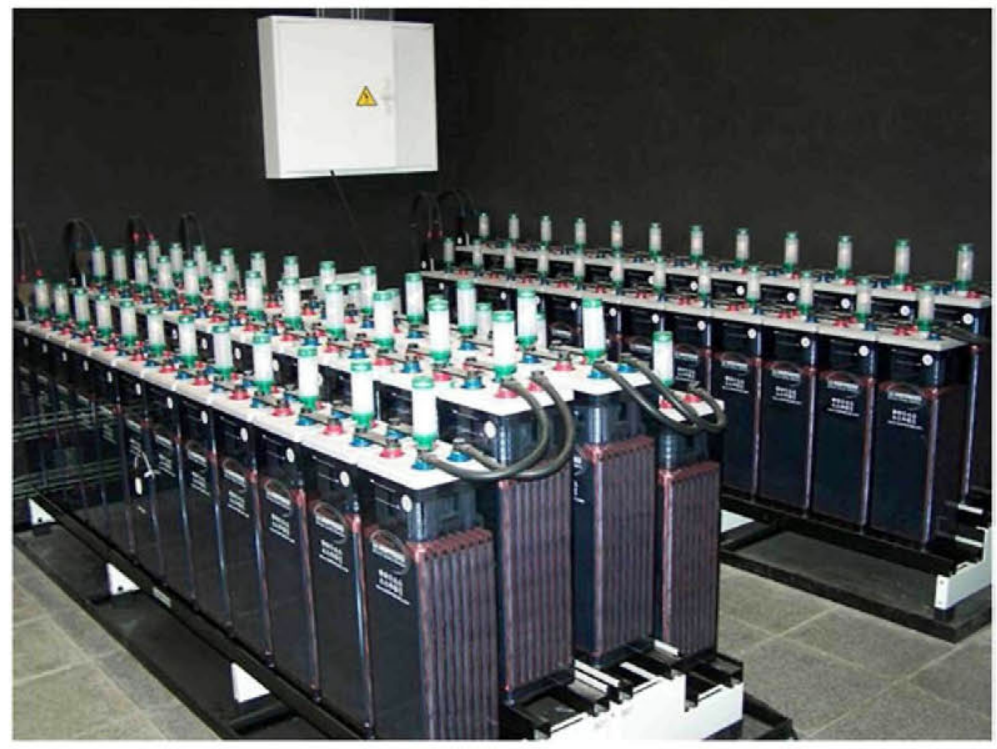

Figure 10. Battery banks. 
With all these data, not only the behaviour of the hybrid system is analysed but also the performance of the CPV generators.

\section{SOFTWARE SIMULATIONS}

Different available software tools have been used to simulate the performance of the hybrid system. In this section, the difficulties presented during the simulations and the results obtained are summarised.

The consumption of the load profile has been generated in different time resolutions: (daily or hourly) depending on the software. The meteorological data have been obtained from the NASA database [15], in order to include the total uncertainty of a standard simulation, where there is no real meteorological data available (Table II).

\subsection{PvSyst software}

The PvSyst software is broadly used to simulate PV plants, because it includes a big database of components and uses hourly resolution for its calculations. It is able to simulate different kinds of systems, including CPV generators as it has already in its database one CPV module (Concentrix FLATCON) [16] from manufacturer SOITEC (Freiburg, Germany).

On the other hand, this software cannot simulate a hybrid system with AC-coupled elements as the one under study. It is mandatory to use a regulator when a stand-alone system is simulated.

This software is able to perform a preliminary calculation with very few data: just the meteorological data and the loads consumption.

From this preliminary simulation, it is obtained that for a system with 1 day of autonomy and a 5\% loss of load probability, the nominal power of the PV generator should be $56.7 \mathrm{~kW}$ (tilt $=30^{\circ}$ ), and the capacity of the battery bank is $520.3 \mathrm{kWh}$. This result is interesting in order to compare it with the CPV simulation.

Once this previous simulation is done, a detailed simulation of the system can be performed. The CPV generator of $58 \mathrm{~kW}$ (very similar to the preliminary simulation result) has been modelled using SOITEC module parameters, without taking into account the differences between the CPV technologies. Hourly consumption profiles have been generated according to the measurements carried out to the load. Although, the previous simulation recommends a bigger storage capacity $(520.3 \mathrm{kWh})$, the system is simulated using its real capacity of $115 \mathrm{kWh}$.

One interesting result is the percentage of the load energy demand that is supplied by the CPV generator (solar fraction). Although the previous calculations showed that with a $58 \mathrm{~kW} \mathrm{CPV}$, a generator is enough to meet the demand of the load in summer when the consumption is higher, because of the limited storage capacity (it is not able to store the energy generated in 1 day), the solar fraction (self-consumption factor) is below $\mathbf{5 0 \%}$ in summer as shown in Figure 11.

Because this software makes calculations with high resolution data, it is possible to have examples of daily profiles. Figure 12 represents a day when the electricity generated is bigger than the consumption, the batteries are at full charge (purple line), and it is not possible to use all the locally generated electricity (unused energy in green). (For the colour version of this figure, readers should be referred to the web version of the paper.)

Extrapolating these data to monthly energy flow (Figure 13), it can be seen that, although it is necessary to use energy from the backup generator most of the months, it is also possible to have the batteries at full charge in some periods of the same month, and in consequence, some energy is unused. As a conclusion, this simulation shows that an active demand management is needed to optimise the CPV generation and the storage of unused energy in the batteries that will be available when it is demanded, resulting in an increased selfconsumption factor.

\subsection{Homer}

Hybrid systems can be simulated with this tool, Homer [17]; even more, the AC-coupled elements can be included in the simulation. Although it is not possible to include the production of a CPV system and the components used are standard, in this way, the accuracy of the simulations is limited.

Table II. Simulation software used to analyse the system.

\begin{tabular}{|c|c|c|c|c|c|}
\hline Name & Developer & Simulates CPV? & $\begin{array}{l}\text { Simulates hybrid } \\
\text { system? }\end{array}$ & $\begin{array}{c}\text { Simulates } \\
\text { AC-coupled? }\end{array}$ & $\begin{array}{l}\text { Granularity of the } \\
\text { consumption data }\end{array}$ \\
\hline PvSyst & $\begin{array}{l}\text { University of } \\
\text { Geneva/PVSYST S.A. }\end{array}$ & Yes & Yes & No & Hour \\
\hline Homer & NREL / Homer Energy & No & Yes & Yes & Day \\
\hline FVDIM & University of Málaga & No & Yes & No & Day \\
\hline Gedelos & UPM-IES & $\begin{array}{l}\text { No (accepts minute } \\
\text { CPV production as } \\
\text { an input) }\end{array}$ & Yes & Yes & Minute \\
\hline
\end{tabular}

CPV, concentration photovoltaics. 


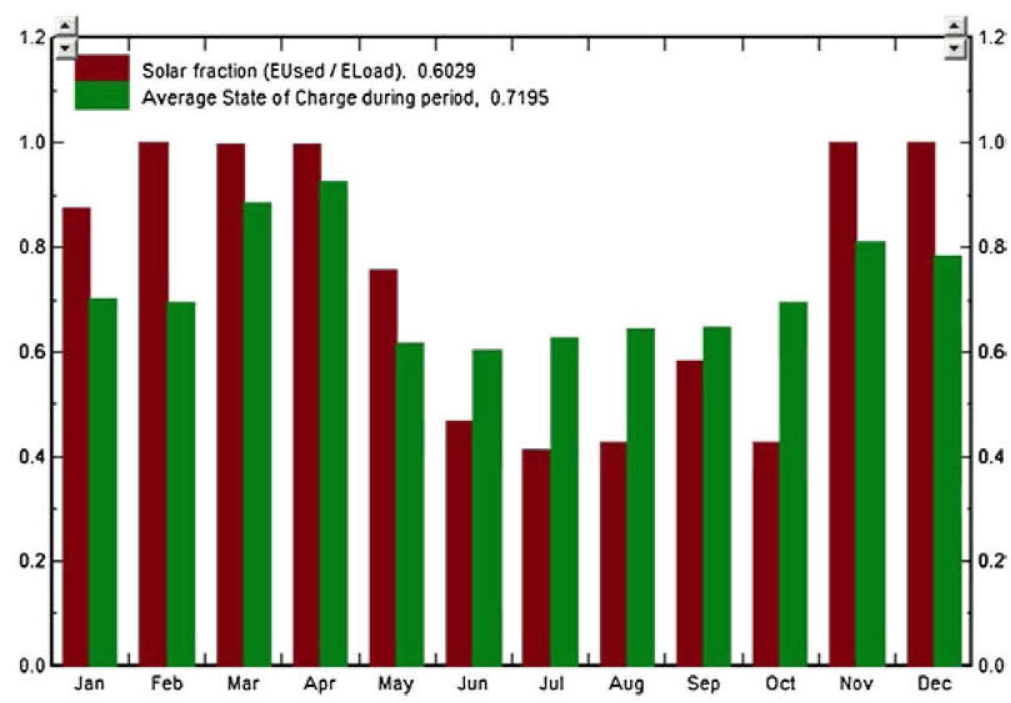

Figure 11. Solar fraction versus average battery SOC.

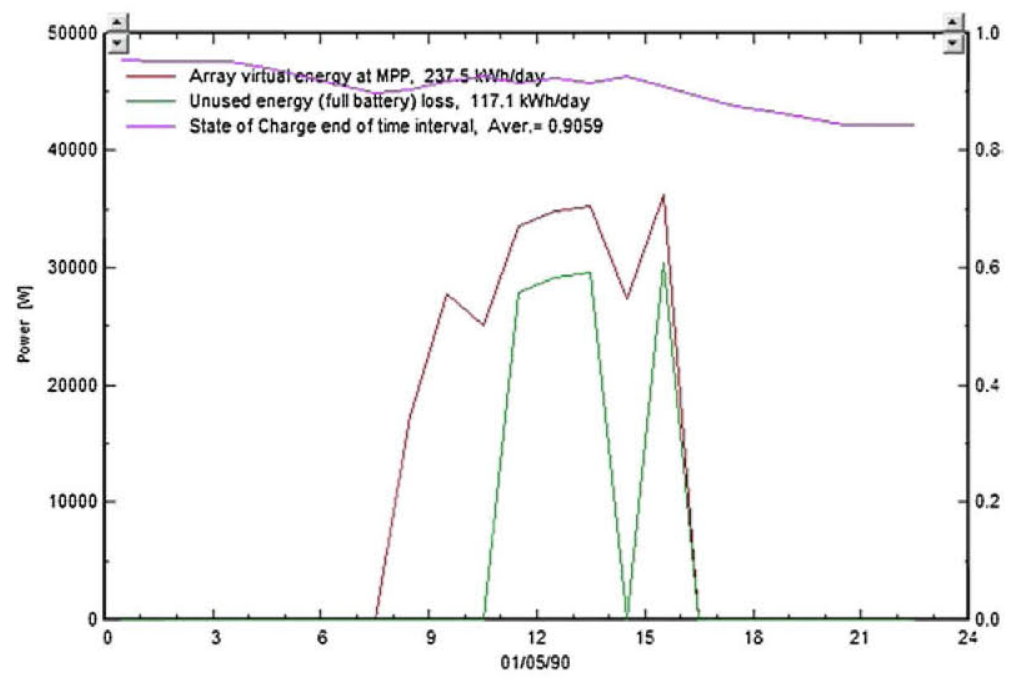

Figure 12. Example of a day with unused energy due to full battery,

Because it is not possible to use a CPV system as an input, for the case under study, PV mounted on a two-axis tracker is used as the main generator. Also, the backup generator used is a diesel generator and not the utility grid.

Homer makes hourly calculations, so that the solar resource and the consumption profile are introduced with hourly resolution.

One interesting result is the fraction of energy supplied to the load by the PV generator and backup generator. As it can be observed in Figure 14, PV feeds most of the energy used by the load, which differs from the result obtained with PvSyst. If, for example, July is analysed, with PVSyst, the amount of energy supplied by the backup was bigger than that supplied by PV, and with Homer, the result is the opposite.
Figure 15 represents the cycling of the batteries. An input for the simulation was the maximum depth of discharge permitted to the batteries that were considered as a $D O D_{\max }$ of $70 \%$. In Figure 15(a), the percentage of time that the batteries are in each state of charge can be observed. It results that in $30 \%$ of the time, the batteries are over $90 \%$. Figure 15(b) represents the cycle of the batteries for each month and the average value for a day. For all the months, the discharge of the batteries is deep, reaching minimum values lower than the $50 \%$. However, it can be observed that the daily cycle is deeper in winter and summer, where the load demand is very high, than in spring and autumn, where there is more energy available with respect to the consumption of the load that is lower. 


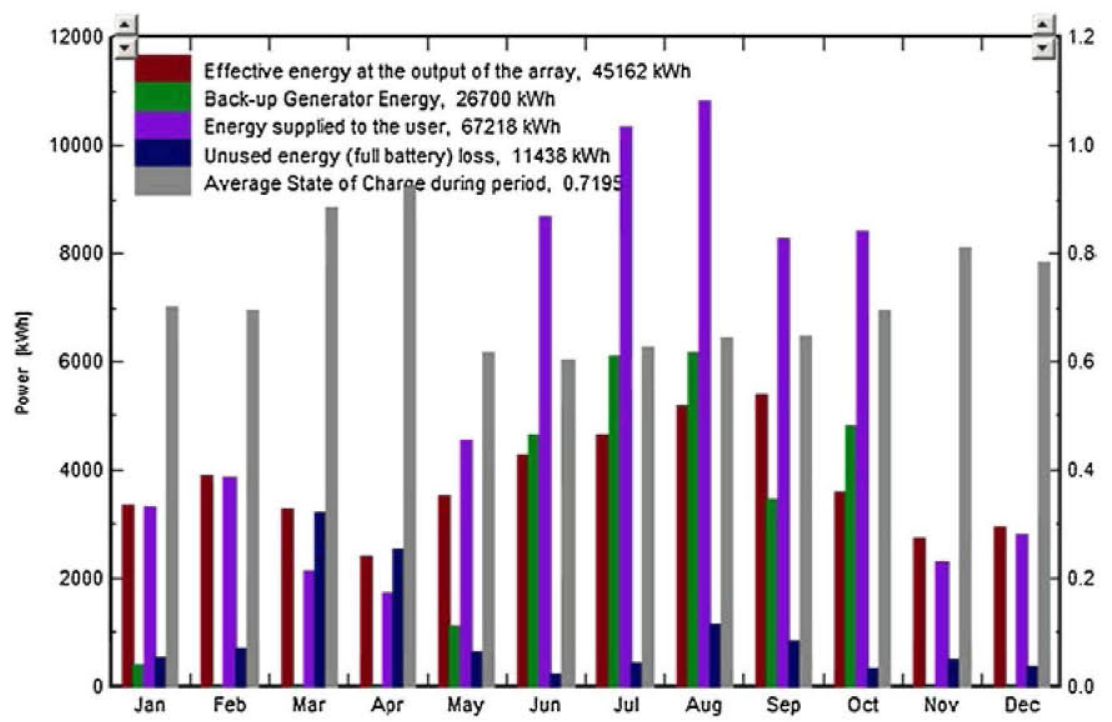

Figure 13. Energy flows, unused energy and battery SOC.

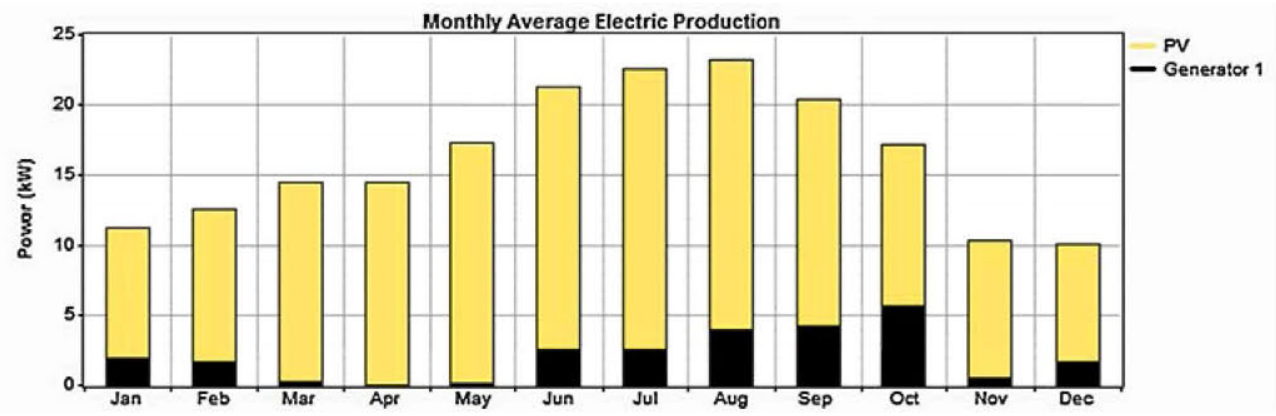

Figure 14. Monthly income of energy from the two generators to the system.

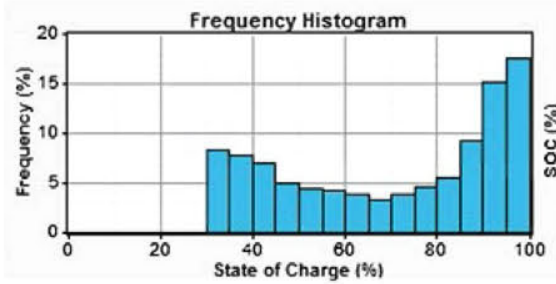

(a)

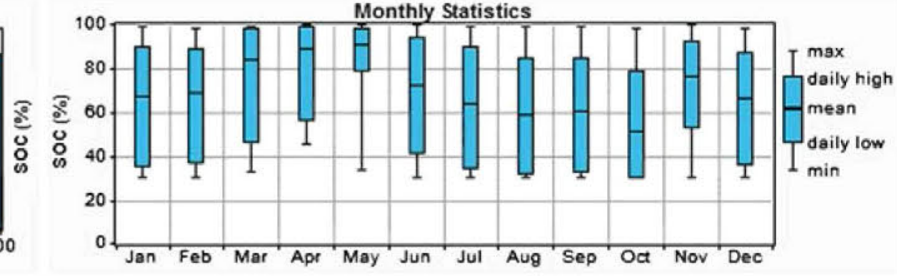

(b)

Figure 15. Battery cycle results (a) frequency histogram and (b) monthly statistics.

\subsection{FVDIM software}

The FVDIM software was developed by the University of Málaga in Spain in 1999. Even though it is neither able to simulate hybrid systems, nor CPV, it is useful for standalone systems with different configurations. The consumption of the load is introduced as a daily value.

In the case under study, a stand-alone system has been simulated with fixed PV and AC loads, which results very far from the real system. The criterion used for making the calculation is based on using the worst month.

The result of this simulation is that a PV generator of $93 \mathrm{~kW}$ and a battery bank of $100573 \mathrm{Ah}$ and $48 \mathrm{~V}$ (4.82 MWh) are necessary to meet the demand. This result also shows that a backup generator is mandatory for such a big system, because in other cases, the size of the PV generator and the storage capacity has to be huge to meet the demand. 


\subsection{Energy balance simulations}

Finally, the simulations of the energy balances of the system permits to know the behaviour of the system in terms of energy used and to design different energy strategies and system modifications for obtaining the biggest profit of the installation in terms of energy used.

In the case under study, the monthly energy balances, self-consumption factor and NER simulations have been calculated using the hourly consumption profile and the real CPV generation profile described in Section 2.2 scaled to $58 \mathrm{~kW}$.

The storage system has been modelled including typical losses of a lead-acid battery bank and battery inverters. Moreover, the battery charge control and the grid energy exchange limitations explained in Section 3 have been included.

Net electricity ratio and self-consumption $(\xi)$ values obtained are plotted in Figure 16(a). On the one hand, NER is bigger than 1 for every month, reaching an average annual value of NER $=1.49$, which denotes a generator oversized in regard to the local consumption. On the other hand, the annual self-consumption is $\xi=0.76$, and this is because the size of the battery bank is not enough to correlate in time the generation with the consumption.

Therefore, there will be CPV energy unused when the batteries are completely charged, and the system will need to import energy from the grid to meet the demand when the generation is not enough and the batteries do not have enough energy stored. Figure 16(b) represents the energy generated and the unused energy. This amount of lost energy could be reduced with a bigger battery capacity, but with an oversized system, it is not possible to avoid the wasted CPV by only modifying the storage capacity.

\subsection{Simulations conclusions}

Some difficulties have been found when simulating a big hybrid system such as the one presented in this paper.

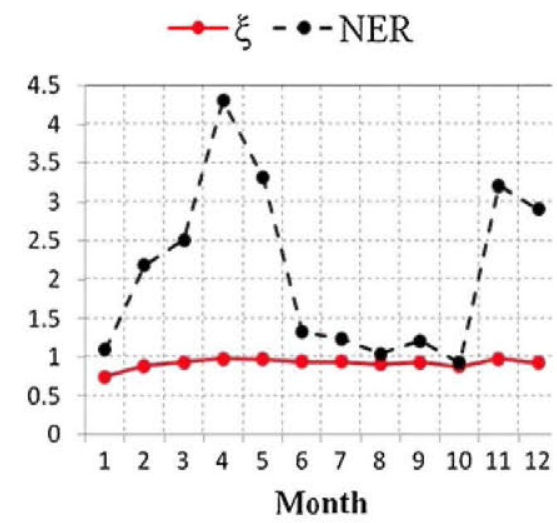

(a)
AC buses are not commonly available, and some software tools cannot simulate systems with high loads consumption such as the air conditioning system here considered. Moreover, nowadays, CPV generators can only be simulated by using PvSyst software. Finally, the energy balance simulations software does not include the possibility to model CPV generation either, but it has been adapted to use the available data from consumption and generation to simulate the behaviour of the hybrid system.

The conclusion obtained from the simulations is that an active management of the demand has to be included to adapt the local consumption to the CPV generation as much as possible. Otherwise, a high percentage of the CPV generation will be wasted, because it is not possible to store it due to the limited size of the storage system. And a high percentage of the electricity demand will be imported from the utility grid (backup generator), thus decreasing the profitability of the system.

\section{SYSTEM MANAGEMENT RESULTS}

This section presents the first experiences of the system management. The main difficulty to deal with is the difference in the load profiles between summer and winter, which means that the management strategies must be also different. First, daily behaviour is analysed for this specific situation; finally, the long term performance of the system is evaluated.

The Multicluster-Box is designed to work with a diesel generator as backup generator, using the programmable relays of the battery inverters to connect and disconnect it. However, as the system installed at ISFOC uses the utility grid as backup generator, the system was not able to disconnect the backup, so it has been continuously connected during the first months. This means that both generators (CPV and utility grid, when CPV is not enough) were always connected, and the batteries were unused as the utility grid can always meet the demand.

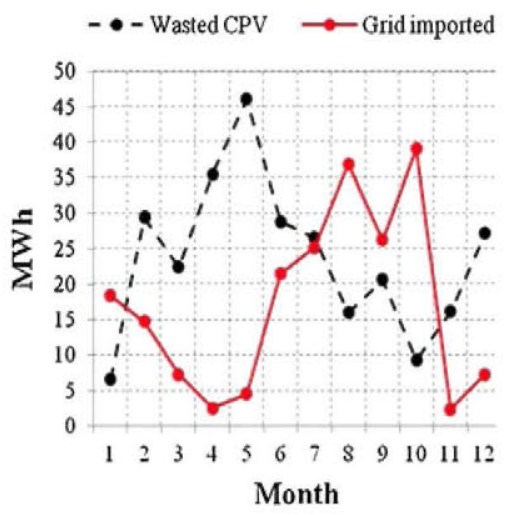

(b)

Figure 16. Monthly data of yearly simulations: (a) self-consumption factor and net energy ratio and (b) energy wasted of the Concentration photovoltaics generator and energy imported from the grid. 


\subsection{Summer}

During this period, the automatic relay for disconnecting the grid was not installed and the nominal power of the CPV generator was only $24 \mathrm{~kW}$.

Therefore, during the first months of operation (summer 2011), if the CPV generator is not meeting the electricity demand, the grid feeds the rest of the electricity (Figure 17). The NER is 0.47 (bigger load than generation, the CPV generator was not complete) and the self-consumption factor $(\xi)$ has the same value, as no energy is taken from the batteries during this period.

As the consumption of the load in summer is quite constant during the working hours, it is easy to manage the system. With a bigger CPV generator, such as the definitive one, the energy generated around midday will be capable to meet the demand, and the excess can be stored in the batteries, being available the rest of the day.

\subsection{Winter}

During this period, the automatic relay for disconnecting the grid was not installed and the nominal power of the CPV generator was only $24 \mathrm{~kW}$. Some manual operation was introduced in the connection/disconnection to the grid in order to test the storage system capacity.

When analysing very cold days in winter, different cases to analyse can be found. Usually, the load profile has a high consumption in the morning until the target temperature of the building is reached, and it is reduced only for maintaining the temperature. In this way, the management of the system is more complex as the load profile is varying along the days.

Figure 18 shows a day where, in the morning, the grid (in red) feeds all the electricity that the load demands (in blue), although the state of charge of the batteries is $100 \%$. Later, when the CPV generator starts to generate (in green), the consumption from the grid is reduced. When

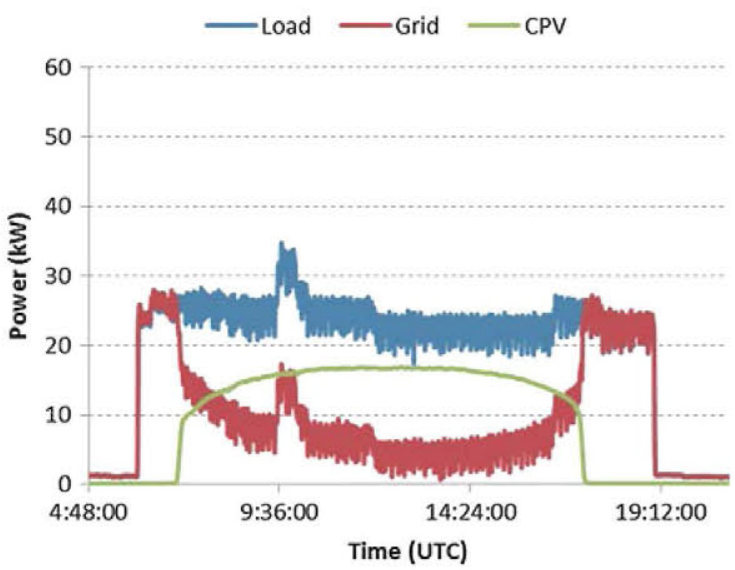

Figure 17. 19 September 2011. Summer day, the consumption of the air conditioning is supplied from the concentration photovoltaics generator and the utility grid.

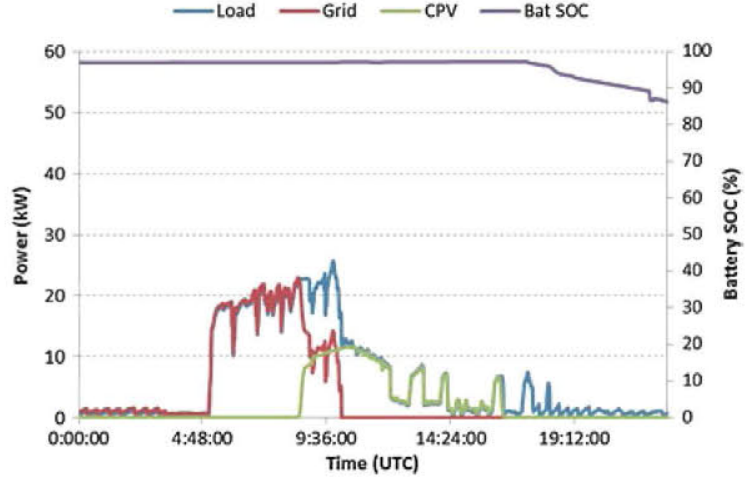

Figure 18. 30 January 2012. Winter day with full-charged batteries.

the demand decreases because the building has reached the target temperature, the CPV generator is limited because the batteries are at full charge (in purple), so all the electricity that the CPV system could generate is wasted. At night, when the CPV generator cannot feed electricity to the air conditioning system, the electricity is taken now from the batteries because the utility grid has been manually disconnected during the day.

This day, the NER is 0.34 . For the self-consumption factor $(\xi)$ calculation, only the energy supplied by the CPV generation to charge the batteries should be taken into account; if this is the case, then $\xi=0.44$. The low value for NER is partially caused by the small size of the CPV generator (only $24 \mathrm{~kW}$ ), and the use of the batteries during the evening improves the $\xi$ factor, but it could be even better if the state of charge of the battery management is improved.

The following day, the system remains disconnected from the grid. Early in the morning, the consumption of the load is high, and the batteries are in charge of feeding the electricity demand until the state of charge reaches $40 \%$ and the load is disconnected; this value is the $D O D_{\max }$ defined (Figure 19). Thus, the grid has to be manually connected again to feed the energy demand and charge the batteries. While the batteries are being charged,

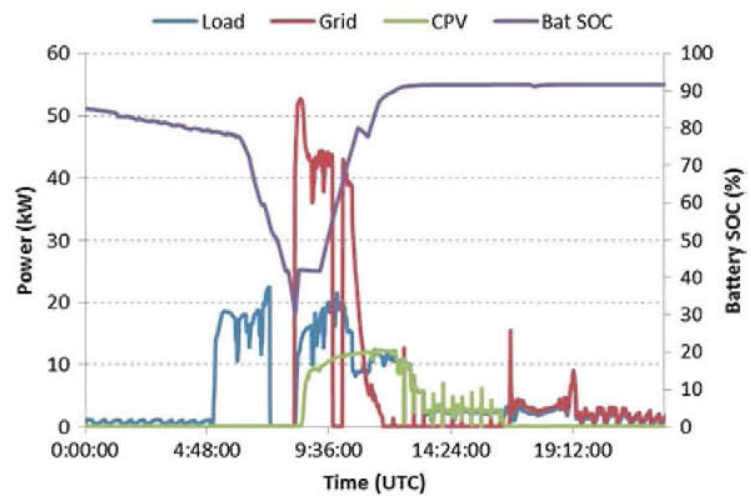

Figure 19. 31 January 2012. Winter day with loss of load, the batteries charged by the grid and generation limitation. 
the CPV generator is feeding its maximum power. However, when the batteries reach a safety value of charge, the CPV generator is limited again, to avoid overcharge.

The NER for 31 January is 0.46 and the selfconsumption factor $(\xi)$ is 0.74 , because a $55 \%$ of the capacity of the batteries is fed to the load.

In winter, the high consumption from the air conditioning system in the morning makes impossible to work in this way. The CPV generation starts later than the consumption, so it will be mandatory to have a huge amount of energy stored in the batteries to be able to fulfil the demand without the grid.

To avoid this kind of situations and once the behaviour of the system was analysed, the automatic contactor for connecting/disconnecting the grid was installed to assure a continuous generation to fulfil the demand. This contactor is commanded by the battery state of charge, it makes the connection to the grid when the state of charge is around $40 \%$ and makes the disconnection when it is around $50 \%$. In this way, there is always available energy and it permits the charge of the batteries with the CPV generator.

\subsection{Spring and autumn}

For this analysis, the installation was modified with the automatic relay for the connection/disconnection from the grid.

In Puertollano, as the climate is not really mild, the air conditioning system changes its operating mode, cooling or heating, from one day to another. However, the consumption levels are smaller as can be seen in Figure 4. Therefore, during these periods, the energy demand can be supplied with the CPV generation and the energy stored in the batteries as it can be observed in Figure 20 . The NER is 1.02 , because the CPV generation is bigger that the load demand, and the self-consumption factor $(\xi)$ goes to 1 , because all the energy needed by the load is taken directly from the CPV generation or the CPV energy stored at the batteries.

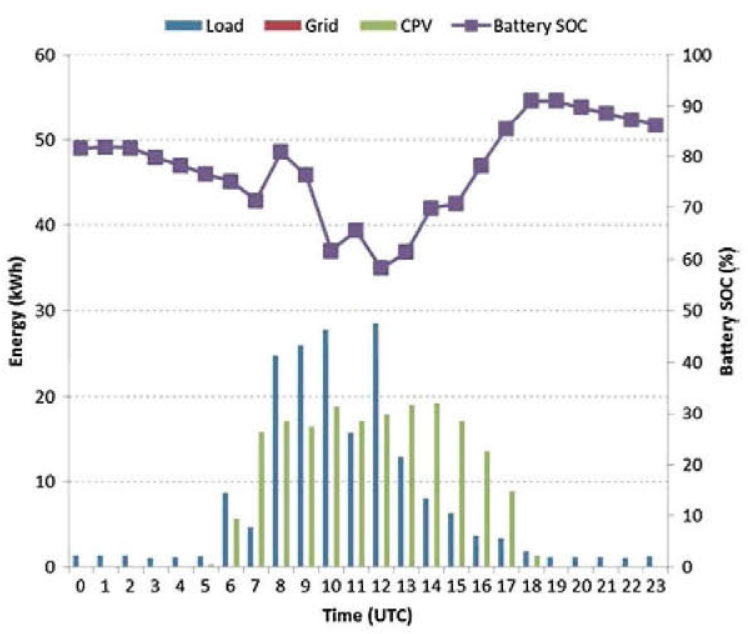

Figure 20. 15 May 2012.
However, because of a non-optimum management of the system, big amounts of energy can be consumed from the grid. On 21 May, as shown in Figure 21, the batteries at the beginning of the day are nearly discharged (state of charge lower than 50\%) from the day before operation; so, when the consumption of the load starts before the CPV generation, some energy has to be imported from the grid to avoid a deep discharge of the battery. Even more, the CPV generation that day was low, so more energy was imported again to recharge the batteries. Finally, when the load consumption decreases, the CPV generator was enough to complete the charge of the batteries without importing energy from the grid.

As it can be observed, the backup generator management with the automatic relay has already been changed. The grid just charges the batteries in the specified range between $40 \%$ and $50 \%$. However, this way of charging, with short charging periods without completing a cycle and letting the battery in deep discharge status, can reduce drastically the life of the batteries. Nevertheless, this is the only way to obtain the maximum available storage capacity for the CPV generation. With an advanced active demand management, the system will be able to avoid this operation mode, permitting it only when the CPV production is supposed to be higher than the consumption, which will permit the complete charge of the battery.

Although the NER is 0.5 during this day, the selfconsumption factor is just 0.3 , because of the bad management of the energy flows.

\subsection{Long-term energy balance}

For making a long term evaluation of the system, only data from May to October 2012 are taken into account, because until May, several modifications were carried out for making the final tuning of the system.

Figure 22 represents the contribution to the total energy income that comes from the CPV generator and the utility grid each month. It is important to remark that the nominal power of the CPV generator was increased in July by connecting a

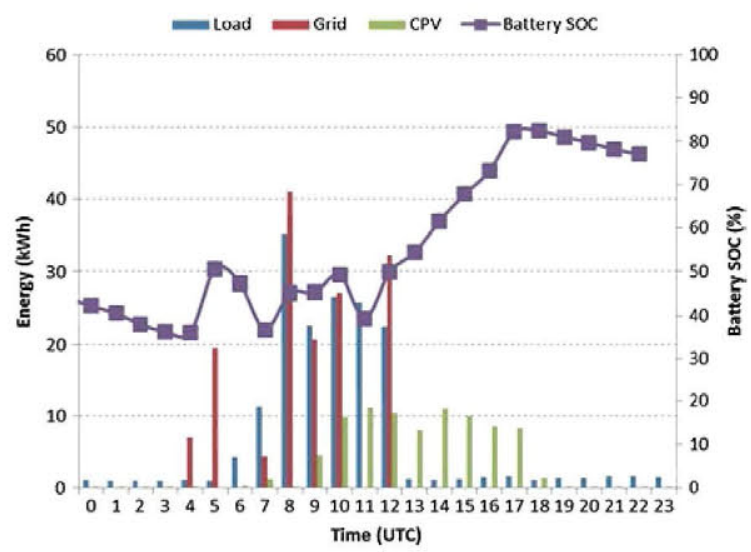

Figure 21. 21 May 2012. 


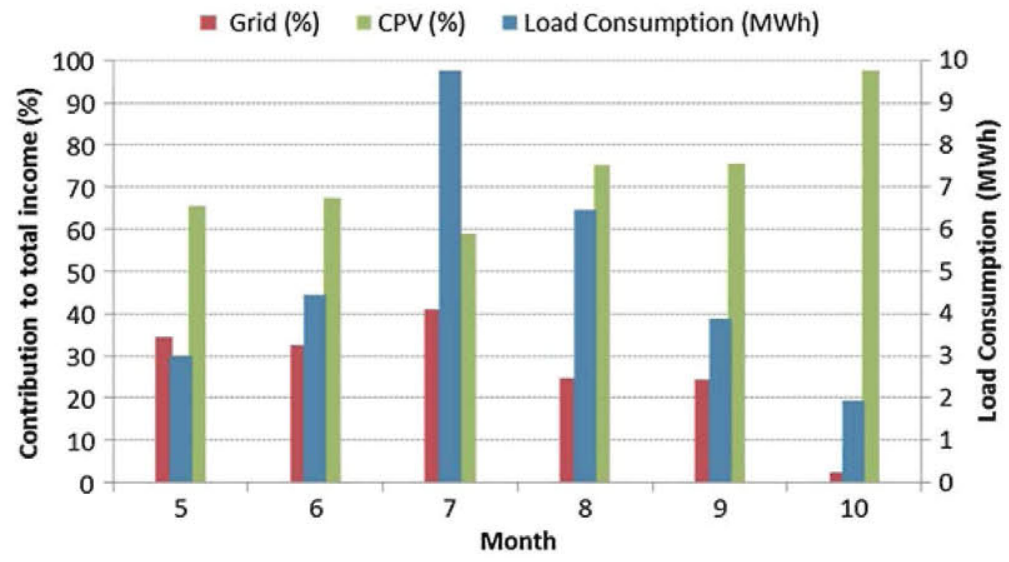

Figure 22. Monthly contribution to total energy income versus load consumption. 1 May-21 October 2012.

new CPV generator. The contribution of the CPV to the total energy income has been over $50 \%$ every month.

The contribution to the total energy income also depends on the DNI, as can be seen in Figure 23. However, as the consumption of the load is bigger in summer (Figure 4(a)), months with higher DNI do not provide months with a higher contribution in percentage from the CPV generator.
Another point that should be analysed is the energy losses due to the fact that the energy is stored in the batteries and later consumed. Figure 24 represents the energy losses of the batteries versus the energy flows of the system. Please note that these losses are smaller on July and August because of the fact that the energy is consumed mainly when it is produced by the CPV generator.

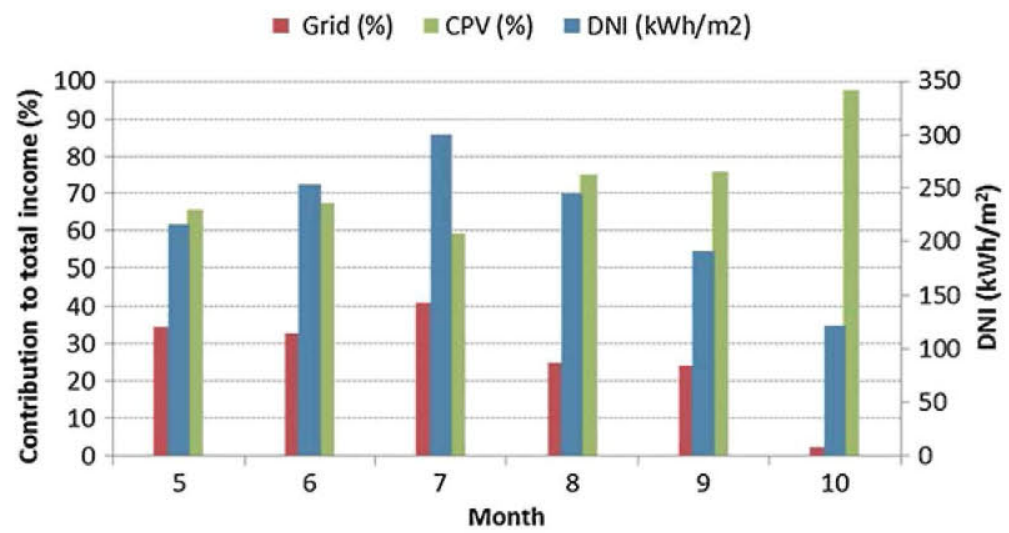

Figure 23. Monthly contribution to total energy income versus direct normal irradiance. 1 May-21 October 2012.

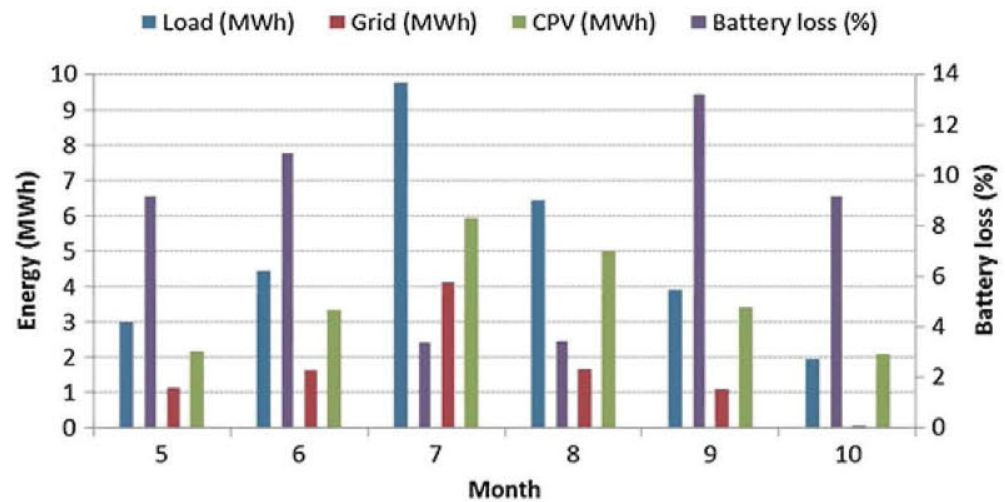

Figure 24. Monthly battery loss versus energy flows. 1 May-21 October 2012. 


\section{CONCLUSIONS}

A new application for CPV systems, namely hybrid CPV systems, is being tested at ISFOC facilities, and it could demonstrate its capability. The first results have been presented along this paper and proved that the management of the load consumption, depending on CPV generation, is of main interest in this system.

In addition, the new self-consumption policies in Spain will determine the management of the system, because it will be possible to feed the excess of energy to the utility grid.

With the current system configuration, it is possible to connect and disconnect the backup generator depending on the battery SOC. Also, the maximum charging current of the batteries can be changed to adapt it to the maximum CPV plant power, avoiding charges from the grid. Finally, the schedule of the air conditioning system can be manually changed for each day of the week. That means that the system will act in a determinate way until an operator changes its parameters. Therefore, the self-consumption factor depends on the ability of the operator to predict the CPV generation in order to select the gap op time when the load can be connected.

The Universidad Politécnica de Madrid-Instituto de Energía Solar (UPM-IES) has been working in active demand site management (ADSM) in a system capable to perform automatic demand side management of residential loads combined with PV generation and forecasts $[5,18,19]$. In the near future, it is intended to adapt such system to the characteristics and conditions of the hybrid system installed at ISFOC, thus an active management of the CPV hybrid system is carried out, adapting the deferrable load profiles to the CPV generation and changing the parameters of the system to maximise the self-consumption of locally generated electricity. In this way, the added-value of CPV electricity to supply the needs of air conditioning systems, whose use is being increased worldwide, will be explored and advanced intelligent energy management strategies proposed,

\section{ACKNOWLEDGEMENTS}

This work is being supported by the Spanish Ministry of Economy and Competitiveness (former Ministry of Science and Innovation) through the INNPACTO Project, 'SIGMAPLANTAS: The innovation on CPV plants and models in Spain', IPS-2011-1468-920000, spin-off of the PSE Project, 'SIGMASOLES: The innovation on CPV in Spain', supported as well by the Spanish government and by the Castilla-La Mancha Regional Government, through its Renewable Energies Program 2010, 'Hybrid System' ERP10/FO/0252.

M. Castillo is sponsored by the Spanish Ministry of Education with a PhD grant (FPU-2010). E. Matallanas is sponsored by the Spanish Ministry of Education with a PhD grant (FPU-2011).
Also, this work will be impossible without the collaboration of DAIDO Steel, Isofotón, Siemens, Semprius, SMA and maintenance and IT groups from ISFOC.

\section{REFERENCES}

1. Vetter M, Schies A, Wachtel J, Prasad Koirala B, Heile I, Gombert A, A Fuad. The world's first CPV standalone system - water supply in remote areas of Egypt, Proceedings 25th European Photovoltaic Solar Energy Conference and Exhibition. 2011.

2. de Estado J. Proyecto de Real Decreto por el que se regula la conexión a red de instalaciones de producción de energía eléctrica de pequeña potencia. Spain, 2011.

3. SMA Solar Technology. The self-consumption bonus. SMA Expert Craftsman Magazine 2010; 1(1).

4. Castillo-Cagigal M, Gutiérrez Á, Monasterio-Huelin F, Caamaño E, Masa D, Jiménez-Leube J. A semidistributed electric demand-side management system with PV generation for self-consumption enhancement. Energy Conversion and Management 2011; 52(7): 2659-2666.

5. Castillo-Cagigal M, Caamaño-Martín E, Matallanas E, Masa-Bote D, Gutiérrez Á, Monasterio-Huelin F, Jiménez-Leube J. PV self-consumption optimization with storage and active DSM for the residential sector. Solar Energy 2011; 85(9): 2338-2348.

6. de la Rubia O, Alamillo C, Trujillo P, Gil E, Rubio F, Banda P. Design \& installation of a CPV hybrid system for self-consumption, 26th European Photovoltaic Solar Energy Conference, 5-9 September 2011, Hamburg, Germany.

7. Trujillo P, Alamillo C, Gil E, de la Rubia Ó, Martínez M, Rubio F, Cadavid A, Navarro J, Hillenbrand S, Ballesteros-Sánchez I, Castillo-Cagigal M, Masa-Bote D, Matallanas E, Caamaño-Martín E, Gutiérrez Á. CPV hybrid system in ISFOC building, first results, 8th International Conference on Concentrating Photovoltaics Systems, April 16-18, Toledo, Spain.

8. Swanson RM. Handbook of Photovoltaic Science and Engineering. Wiley: New Jersey, 2008; 449-501.

9. Kinsey G. Solar Cells and Their Application. Second edn. Wiley: New Jersey, 2010; 293-312.

10. King RR, Bhusari D, Larrabee D, Liu X-Q, Rehder E, Edmondson K, Cotal H, Jones RK, Ermer JH, Fetzer CM, Law DC, Karam NH. Solar cell generations over $40 \%$ efficiency. 26th European Photovoltaic Solar Energy Conference, 5-9 September 2011, Hamburg, Germany.

11. Record solar cell efficiencies for multijunction concentrator cells and other photovoltaic technologies since 1975, as compiled by the National Renewable Energy Laboratory (NREL). http://www.nrel.gov/ncpv/images/ efficiency_chart.jpg 
12. Ghosal K, Lilly D, Gabriel J, Seel S, Menard E, Burroughs S, Daniel R, Lowe S, Kudija C. Performance of a microcell based transfer printed HCPV system in the south eastern US. 8th International Conference on Concentrating Photovoltaics Systems, April 16-18, Toledo, Spain.

13. Rubio F, Pachón JL, Hofmann O, Banda P. Establishment of the Institute of Concentration Photovoltaics Systems-ISFOC. $4^{\text {th }}$ International Conference on Solar Concentrators for the Generation of Electricity or Hydrogen, San Lorenzo del Escorial, Spain, 12-16 March 2007.

14. Thim F, Rothert M, Wachenfeld V, Landau M. 10 years field experience with modular AC-coupled off-grid systems. 26th European Photovoltaic Solar Energy Conference, 5-9 September 2011, Hamburg, Germany.

15. NASA surface meteorology and solar energy. http:// eosweb.larc.nasa.gov/sse/. Accessed May 2012
16. Gerstmaier T, van Riesen S, Gombert A, Mermoud A, Lejeune T, Duminil E. "Software modeling of FLATCONO CPV systems", $6^{\text {th }}$ International conference on concentrating photovoltaic systems: CPV-6". AIP Conference Proceedings, Volume 1277, 2010, pp. 183-186

17. Lilienthal P. The HOMER micropower optimization model. Presented at 2004 DOE solar energy technologies. Program Review Meeting. Denver, Colorado. October 25-28, 2004.

18. Masa-Bote $D^{*}$, Caamaño-Martín E. Forecast of energy production for PV systems 24 hours ahead. 25th European Photovoltaic Solar Energy Conference and Exhibition / 5th World Conference on Photovoltaic Energy Conversion, 6-10 September 2010, Valencia, Spain.

19. Matallanas E, Castillo-Cagigal M, Gutiérrez Á, Monasterio-Huelin F, Caamaño-Martín E, Masa-Bote D, Jiménez-Leube J. Neural network controller for active demand-side management with PV energy in the residential sector. Applied Energy 2012; 91: 90-97. 